\title{
S100A4 Is a Biomarker of Tumorigenesis, EMT, Invasion, and Colonization of Host Organs in Experimental Malignant Mesothelioma
}

\author{
Joëlle S. Nader ${ }^{1,+}$, Jordan Guillon ${ }^{2,+}$, Coralie Petit ${ }^{2,+}$, Alice Boissard ${ }^{3}$, Florence Franconi ${ }^{4}$ (D), \\ Stéphanie Blandin ${ }^{5}$, Sylvia Lambot ${ }^{1}$, Marc Grégoire ${ }^{6}$, Véronique Verrièle ${ }^{3}$, \\ Béatrice Nawrocki-Raby ${ }^{7}$, Philippe Birembaut ${ }^{7,8}$, Olivier Coqueret ${ }^{2}$ (D) , Catherine Guette ${ }^{3}$ \\ and Daniel L. Pouliquen $2, *$ (D) \\ 1 Université de Nantes, Inserm, CRCINA, F-44000 Nantes, France; joelle03nader@gmail.com (J.S.N.); \\ sylvia.lambot@inserm.fr (S.L.) \\ 2 Université d'Angers, Inserm, CRCINA, F-44000 Nantes, France; jordanguillon5@gmail.com (J.G.); \\ coralie.petit49@gmail.com (C.P.); olivier.coqueret@univ-angers.fr (O.C.) \\ 3 Université d'Angers, ICO Cancer Center, Inserm, CRCINA, F-44000 Nantes, France; \\ alice.boissard@ico.unicancer.fr (A.B.); veronique.verriele@ico.unicancer.fr (V.V.); \\ catherine.guette@ico.unicancer.fr (C.G.) \\ 4 Université d'Angers, PRISM Plate-forme de Recherche en imagerie et spectroscopie multi-modales, \\ F-49000 Angers, France; florence.franconi@univ-angers.fr \\ 5 Université de Nantes, Plate-forme MicroPICell, SFR François Bonamy, F-44000 Nantes, France; \\ stephanie.blandin@univ-nantes.fr \\ 6 Université de Nantes, Inserm, CRCINA, SIRIC ILIAD, F-44000 Nantes, France; marc.gregoire@inserm.fr \\ 7 Université de Reims Champagne Ardenne, Inserm, P3Cell UMR-S 1250, SFR CAP SANTE, \\ F-51092 Reims, France; beatrice.raby@univ-reims.fr \\ 8 CHU de Reims, Hôpital Maison Blanche, Laboratoire de Pathologie, F-51092 Reims, France; \\ pbirembaut@chu-reims.fr \\ * Correspondence: daniel.pouliquen@inserm.fr; Tel.: +33-2-41-35-28-54 \\ + Co-first authors.
}

Received: 9 March 2020; Accepted: 8 April 2020; Published: 10 April 2020

check for updates

\begin{abstract}
Recent findings suggest that S100A4, a protein involved in communication between stromal cells and cancer cells, could be more involved than previously expected in cancer invasiveness. To investigate its cumulative value in the multistep process of the pathogenesis of malignant mesothelioma (MM), SWATH-MS (sequential window acquisition of all theoretical fragmentation spectra), an advanced and robust technique of quantitative proteomics, was used to analyze a collection of 26 preneoplastic and neoplastic rat mesothelial cell lines and models of MM with increasing invasiveness. Secondly, proteomic and histological analyses were conducted on formalin-fixed paraffin-embedded sections of liver metastases vs. primary tumor, and spleen from tumor-bearing rats vs. controls in the most invasive MM model. We found that S100A4, along with 12 other biomarkers, differentiated neoplastic from preneoplastic mesothelial cell lines, and invasive vs. non-invasive tumor cells in vitro, and MM tumors in vivo. Additionally, S100A4 was the only protein differentiating preneoplastic mesothelial cell lines with sarcomatoid vs. epithelioid morphology in relation to EMT (epithelial-to-mesenchymal transition). Finally, S100A4 was the most significantly increased biomarker in liver metastases vs. primary tumor, and in the spleen colonized by MM cells. Overall, we showed that S100A4 was the only protein that showed increased abundance in all situations, highlighting its crucial role in all stages of MM pathogenesis.
\end{abstract}

Keywords: S100A4; malignant mesothelioma; EMT; invasiveness; colonization; proteomics; SWATH-MS; biomarkers; rat tumor model 


\section{Introduction}

Identifying key molecular components and the sequence of events that occurs is a crucial step in understanding the tumor metastasis process. For this purpose, a number of proteins were selected, of which S100A4, an important member of the S100 protein family, actively participates in tumor progression and metastasis in various malignant tumors [1]. Moreover, in the context of a pre-metastatic niche [2], S100A4 production serves as a link between inflammation and tumor metastasis, and is indicative of poor prognosis [3].

The acquisition of a metastatic phenotype is associated with the re-activation of the epithelial-to-mesenchymal transition (EMT) [4], which also involves the hypoxia-inducible factor HIF-1 [5]. The contribution of S100A4 to the EMT process has been demonstrated in patients, being particularly highly expressed in the peripheral leading edge of breast cancer [6], and experimentally in a context of transformation of a non-metastatic human prostate cancer cell line, which leads to the cancers' acquiring invasive properties [7]. The combined gain of S100A4 and loss of membrane E-cadherin in cervical cancer tends to confirm its link with an unfavorable prognosis [8]. Moreover, the role of this biomarker as a central node in a molecular network controlling stemness and EMT has been reported in one of the most aggressive tumors, glioblastoma [9], providing the initial parts of an answer to the question of the relationship between these two processes [10].

Malignant mesothelioma (MM) has one of the worst clinical outcomes, especially its sarcomatoid histological subtype, because of the complex biology of this cancer due to its mesenchymal "pluripotent" origin. Moreover, EMT appears to represent a permanent feature of the sarcomatoid subtype, with a deleterious impact on its prognosis [11]. These peculiarities explain the very modest success of the various therapies applied [12,13], and the challenge of diagnosis and prognosis of this pathology. For these reasons, further studies are required in order to fully understand MM molecular pathogenesis and to develop new target agents [14], particularly for the sarcomatoid subtype, for which current biomarkers are not valid [15]. To fulfill the need for new biomarkers that are effective for MM [16], our team previously demonstrated that SWATH-MS (sequential window acquisition of all theoretical fragmentation spectra), an advanced and robust quantitative proteomics technique, can be applied to the analysis of experimental MM tumor specimens to characterize increasing stages of invasiveness [17].

In this study, our aim was to determine whether S100A4, one of the most important biomarkers for invasiveness, previously identified in a list of 137 proteins [17], was involved in all stages of MM pathogenesis, including tumorigenesis, EMT, invasion, and colonization of host organs, and whether it presented a comparable evolution during the whole process when used alone or when combined with other proteins of interest. Our experimental approach was based on the use of a large biocollection of rat cell lines and MM tumor models [18]. Rat models of MM have been successfully used for decades to decipher the different stages of MM molecular pathogenesis [19]. The immunocompetent inbred F344 rat strain F344 is a good experimental base for designing syngeneic orthotopic tumor models, which are preferable when considering tumor versus immune cell interactions $[17,20]$, and when evaluating the therapeutic efficacy of new drugs [21]. Moreover, this type of experimental model allows MRI monitoring [22]. We used such a model so as to benefit from its genetically identical base, as all individuals bear the same Major Histocompatibility Complex (MHC) haplotype in the RT1 region $\left(R T 1^{\mathrm{lv}}\right)$, a situation which potentially limits the source of potential variation in the results when contrasting with humans, while mimicking some of the worst clinical conditions encountered in patients.

\section{Results}

\subsection{S100A4, a Biomarker for Neoplastic Transformation, EMT, and In Vitro Invasiveness}

During the first step, SWATH-MS analysis of the whole biocollection of rat mesothelial cell lines detected 1661 proteins in each cell line. The number of proteins with significantly different abundances, allowing to differentiate between the groups of neoplastic cell lines (C3) and preneoplastic cell lines 
with epithelioid (C1) or sarcomatoid morphology (C2) [18], was 863 and 856 proteins, respectively. Crossing the two files produced 595 common proteins representing potential biomarkers for neoplastic transformation (Figure 1A). Secondly, this tumorigenesis list of 595 proteins was crossed with an invasiveness list consisting of 251 proteins, presenting significantly different abundances between the three invasive neoplastic cell lines (F4-T2, F5-T1, and M5-T1) (C4) relative to the non-invasive M5-T2 cell line (C5) (Figure 1A). This produced 90 proteins representing potential biomarkers for both neoplastic transformation and in vitro invasiveness (Figure 1B). In parallel, two lists of biomarkers differentiating the two groups of preneoplastic cell lines with sarcomatoid, PNsarc (C2), and epithelioid, PN-[Epith] (C1) morphologies [18], and the two subgroups, PNsarc2 and PNsarc1 (Table 1), were established, consisting of 674 and 192 proteins, respectively. Crossing these two lists with the 90 proteins described above produced one single protein, S100A4 (Figure 1B), that showed an increased abundance between the two groups of preneoplastic cell lines (Figure 1C). This result appeared to be related to EMT, as a significant rise in the abundance of fibronectin and vimentin, two important markers of this process [23], was concomitantly observed (Supplementary Figure S1).

Given the suggested role of oxidative stress in mesothelial carcinogenesis by promoting EMT processes, particularly with the involvement of Hif1a [24], an investigation of its expression profile and 14 other genes coding for various factors (Ccl3, Ccl5, Ccl7, Egf, Erbb2, Fgf2, Fhit, Il1b, Il6, Nfkb1, Pdgfa, Stat3, Tnf, and Vegfa) [25] revealed that the increased expression of Hif1a in PNsarc2 versus PNsarc1 (Table 1) was linked to the expression of Vegfa, CCl7, and Stat3 (Figure 2).

A

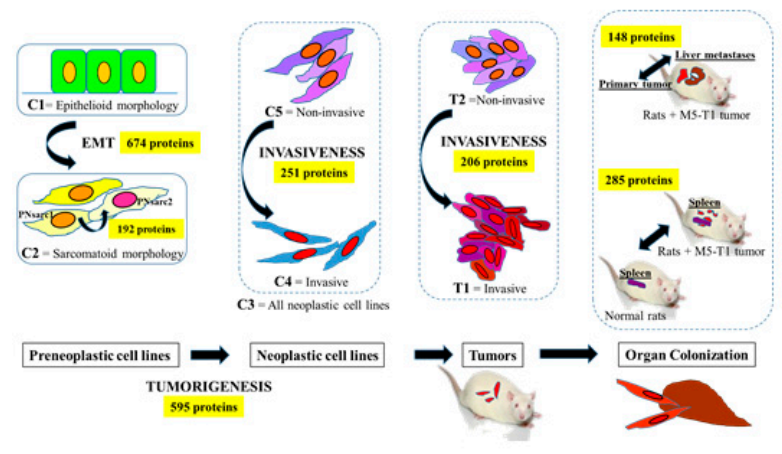

B

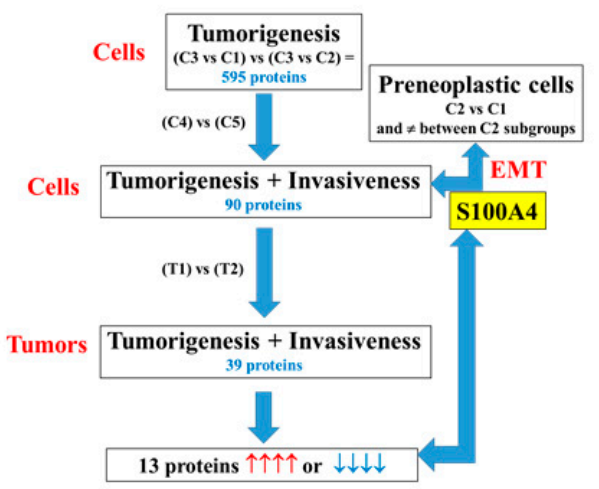

C
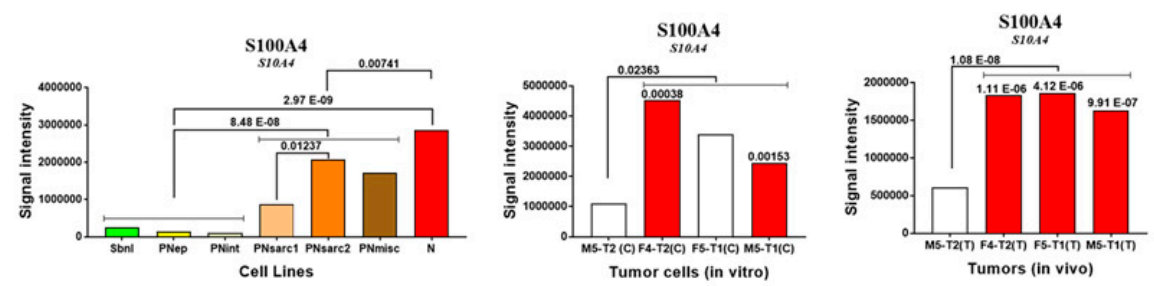

Figure 1. Identification of S100A4 as the main biomarker. (A) Scheme of the successive steps and sources of data used for the identification of candidate biomarkers. C1, preneoplastic cell lines with epithelioid morphology. C2, preneoplastic cell lines with sarcomatoid morphology. C3, neoplastic cell lines. C4, invasive neoplastic cell lines. C5, non-invasive neoplastic cell line. T1, invasive MM (malignant mesothelioma) tumors. T2, non-invasive MM tumor. (B) Methodology used for SWATH-MS (sequential window acquisition of all theoretical fragmentation spectra) proteomic analyses of cell lines and tumors. (C) Comparative proteomic abundances of S100A4 (significant increases in red and decreases in blue, with $p$ values). Left: comparison between the different subgroups and groups of preneoplastic and neoplastic cell lines (in vitro); middle: comparison between invasive and non-invasive neoplastic cell lines (in vitro); right: comparison between invasive and non-invasive mesotheliomas (in vivo). Blank bars correspond to the absence of significant differences between cell lines/tumors. 
Table 1. Classification of the biocollection of rat mesothelial cell lines. Roulois et al. [18] showed photographs of each cell line at confluence and their growth characteristics (Supplementary Figure S2 and Table S1, respectively).

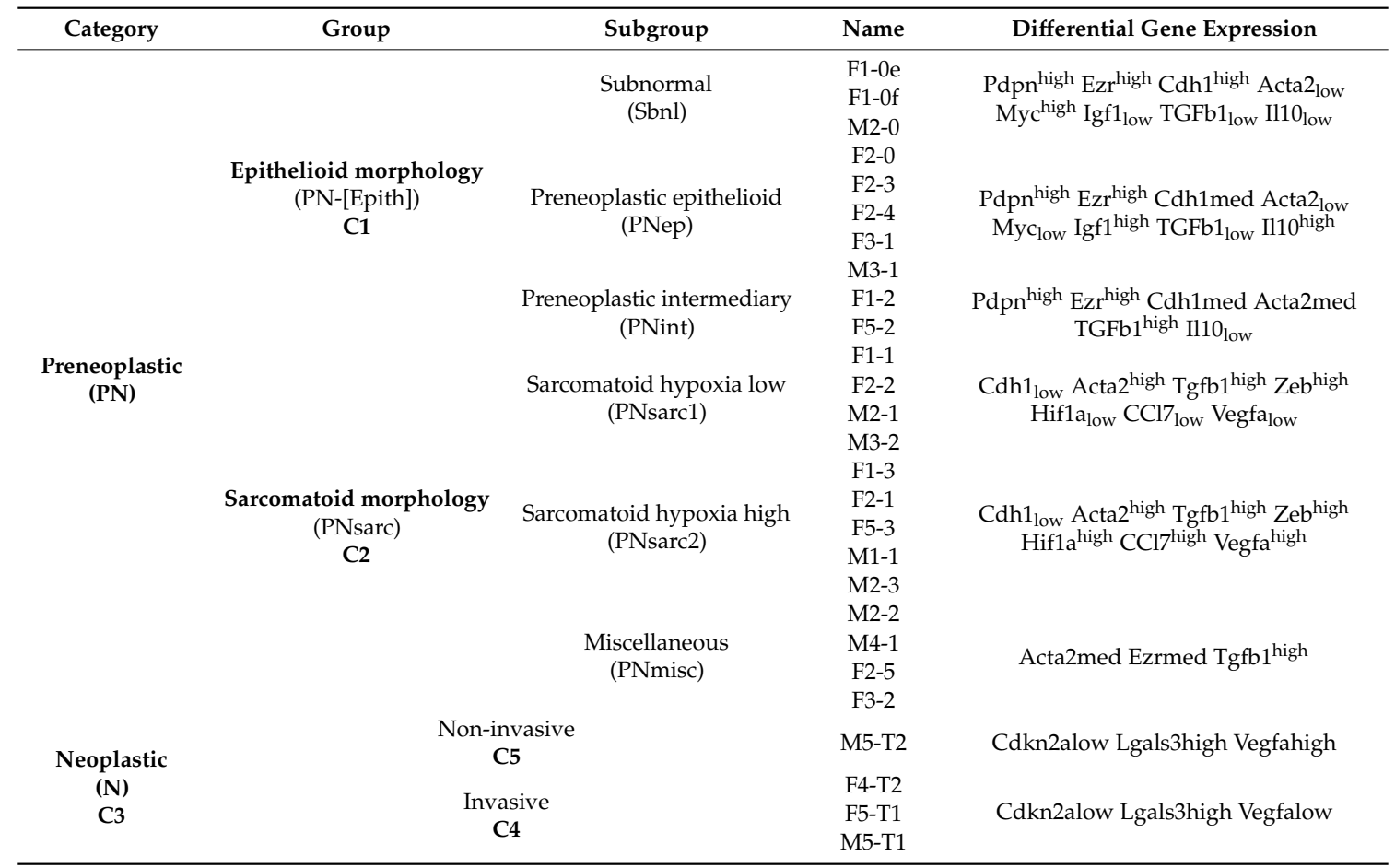
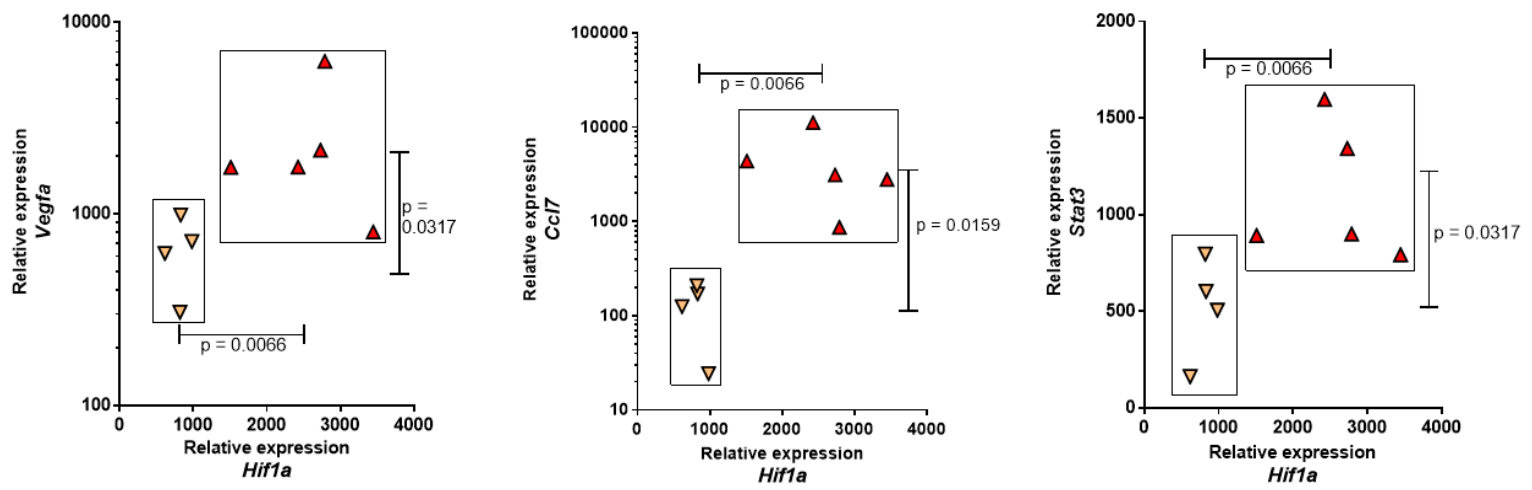

Figure 2. Differential expression of Hifla within preneoplastic cell lines with sarcomatoid morphology (PNsarc, C2). Expression of Hif1a in the two subgroups (PNsarc1 in yellow, PNsarc2 in red triangles) of rat preneoplastic mesothelial cell lines with sarcomatoid morphology and their relationships with Vegfa, Ccl7, and Stat3 expressions.

\subsection{S100A4, Biomarker of In Vivo Invasiveness}

As a third step, the previous list of 90 proteins that characterized both neoplastic transformation and in vitro invasiveness in cells was crossed with a new list of 206 proteins (Figure 1A) that differentiated the three invasive MM tumors from the non-invasive one. This produced a reduced list of 39 potential biomarkers for both neoplastic transformation and in vitro and in vivo invasiveness (Figure 1B). Finally, the four analyses produced 13 proteins (Figure 1B), for which quantitative changes corresponded to increases or decreases in all situations (Table 2). For these 13 proteins, additional information was collected, such as the mean differences observed not only between groups, but also between subgroups of preneoplastic cells, or between individual invasive neoplastic cell lines or tumors versus the non-invasive ones. Among these 13 proteins, S100A4 was the only one to exhibit a continuous and significant increase in abundance from preneoplastic cell lines with epithelioid and 
sarcomatoid morphology to neoplastic cells, and from non-invasive to invasive MM cells and tumors (Figure 1C). Five proteins presented a common increase in abundance: Annexin A5, prelamin-A/C, barrier-to-autointegration factor, histone H2A.J, and glutathione reductase (Supplementary Figure S2). Seven proteins showed a common decrease in abundance: Septin-2, dihydropyrimidinase-related protein 2, myosin-10, the mitochondrial aconitate hydratase, leucine zipper protein 1, echinoderm microtubule-associated protein-like 2, and 5-oxoprolinase (Supplementary Figure S2).

Table 2. List of candidate markers of interest, identified via the different methodological steps described in Figure 1B. The 13 proteins for which abundances changed significantly $(p<0.05)$ in the same way in the different situations are highlighted in yellow (increase) or green (decrease).

\begin{tabular}{|c|c|c|c|c|c|}
\hline Code & Name & $\mathrm{C} 3$ vs. $\mathrm{C} 1$ & $\mathrm{C} 3$ vs. C2 & C4 vs. C5 & T1 vs. T2 \\
\hline ACADL & Long-chain specific acyl-CoA dehydrogenase, mitochondrial & $\downarrow$ & $\downarrow$ & $\downarrow$ & $\uparrow$ \\
\hline $\mathrm{ACON}$ & Aconitate hydratase, mitochondrial & $\downarrow$ & $\downarrow$ & $\downarrow$ & $\downarrow$ \\
\hline ACTN4 & Alpha-actinin-4 & $\uparrow$ & $\downarrow$ & $\downarrow$ & $\downarrow$ \\
\hline ANXA2 & Annexin A2 & $\uparrow$ & $\uparrow$ & $\uparrow$ & $\downarrow$ \\
\hline ANXA5 & Annexin A5 & $\uparrow$ & $\uparrow$ & $\uparrow$ & $\uparrow$ \\
\hline ATPO & ATP synthase subunit $\mathrm{O}$, mitochondrial & $\uparrow$ & $\uparrow$ & $\downarrow$ & $\uparrow$ \\
\hline BAF & Barrier-to-autointegration factor & $\uparrow$ & $\uparrow$ & $\uparrow$ & $\uparrow$ \\
\hline DPYL2 & Dihydropyrimidinase-related protein 2 & $\downarrow$ & $\downarrow$ & $\downarrow$ & $\downarrow$ \\
\hline EDF1 & Endothelial differentiation-related factor 1 & $\uparrow$ & $\uparrow$ & $\downarrow$ & $\downarrow$ \\
\hline EMAL2 & Echinoderm microtubule-associated protein-like 2 & $\downarrow$ & $\downarrow$ & $\downarrow$ & $\downarrow$ \\
\hline FKB1A & Peptidyl-prolyl cis-trans isomerase FKBP1A & $\uparrow$ & $\uparrow$ & $\downarrow$ & $\downarrow$ \\
\hline GSHR & Glutathione reductase & $\uparrow$ & $\uparrow$ & $\uparrow$ & $\uparrow$ \\
\hline $\mathrm{H} 2 \mathrm{AJ}$ & Histone H2A.J & $\uparrow$ & $\uparrow$ & $\uparrow$ & $\uparrow$ \\
\hline H31 & Histone H3.1 & $\downarrow$ & $\downarrow$ & $\uparrow$ & $\uparrow$ \\
\hline HYOU1 & Hypoxia up-regulated protein 1 & $\downarrow$ & $\uparrow$ & $\downarrow$ & $\downarrow$ \\
\hline ICAL & Calpastatin & $\downarrow$ & $\downarrow$ & $\uparrow$ & $\uparrow$ \\
\hline IF6 & Eukaryotic translation initiation factor 6 & $\downarrow$ & $\downarrow$ & $\downarrow$ & $\uparrow$ \\
\hline LMNA & Prelamin-A/C & $\uparrow$ & $\uparrow$ & $\uparrow$ & $\uparrow$ \\
\hline LUZP1 & Leucine zipper protein 1 & $\downarrow$ & $\downarrow$ & $\downarrow$ & $\downarrow$ \\
\hline MOES & Moesin & $\uparrow$ & $\uparrow$ & $\downarrow$ & $\downarrow$ \\
\hline MYH10 & Myosin-10 & $\downarrow$ & $\downarrow$ & $\downarrow$ & $\downarrow$ \\
\hline NCAM1 & Neural cell adhesion molecule 1 & $\uparrow$ & $\uparrow$ & $\downarrow$ & $\downarrow$ \\
\hline NDKB & Nucleoside diphosphate kinase B & $\uparrow$ & $\uparrow$ & $\downarrow$ & $\downarrow$ \\
\hline NDRG1 & Protein NDRG1 & $\downarrow$ & $\downarrow$ & $\downarrow$ & $\uparrow$ \\
\hline OPLA & 5-oxoprolinase & $\downarrow$ & $\downarrow$ & $\downarrow$ & $\downarrow$ \\
\hline PA1B2 & Platelet-activating factor acetylhydrolase IB subunit beta & $\uparrow$ & $\uparrow$ & $\downarrow$ & $\downarrow$ \\
\hline PHB & Prohibitin & $\downarrow$ & $\downarrow$ & $\uparrow$ & $\uparrow$ \\
\hline PRDX3 & Thioredoxin-dependent peroxide reductase, mitochondrial & $\uparrow$ & $\uparrow$ & $\downarrow$ & $\downarrow$ \\
\hline RLA0 & $60 S$ acidic ribosomal protein $\mathrm{P} 0$ & $\uparrow$ & $\uparrow$ & $\uparrow$ & $\downarrow$ \\
\hline RTCB & tRNA-splicing ligase RtcB homolog & $\downarrow$ & $\downarrow$ & $\downarrow$ & $\uparrow$ \\
\hline S10A4 & Protein S100-A4 & $\uparrow$ & $\uparrow$ & $\uparrow$ & $\uparrow$ \\
\hline SEPT2 & Septin-2 & $\downarrow$ & $\downarrow$ & $\downarrow$ & $\downarrow$ \\
\hline STABP & STAM-binding protein OS = Rattus norvegicus & $\downarrow$ & $\downarrow$ & $\downarrow$ & $\uparrow$ \\
\hline TBCA & Tubulin-specific chaperone A & $\downarrow$ & $\downarrow$ & $\uparrow$ & $\uparrow$ \\
\hline TBG1 & Tubulin gamma-1 chain & $\downarrow$ & $\downarrow$ & $\uparrow$ & $\uparrow$ \\
\hline TCTP & Translationally-controlled tumor protein & $\uparrow$ & $\uparrow$ & $\downarrow$ & $\downarrow$ \\
\hline TYB10 & Thymosin beta-10 & $\uparrow$ & $\uparrow$ & $\downarrow$ & $\downarrow$ \\
\hline UB2V2 & Ubiquitin-conjugating enzyme E2 variant 2 & $\uparrow$ & $\uparrow$ & $\downarrow$ & $\downarrow$ \\
\hline UGGG1 & UDP-glucose:glycoprotein glucosyltransferase 1 & $\downarrow$ & $\downarrow$ & $\uparrow$ & $\uparrow$ \\
\hline
\end{tabular}

To evaluate a possible human MM application deriving from these findings, we conducted a preliminary investigation on two tumor samples from the Tumor Bank of the Reims University Hospital Biological Resources, Collection n AC-2019-340, declared at the Ministry of Health, according to the French Law for the use of tissue samples for research. A comparative SWATH-MS analysis of two paraffin-embedded human MM tumor pieces (sarcomatoid vs. epithelioid, Supplementary Figure S3) revealed a significant increase in S100A4 abundance in both the tumor and its periphery, and concomitantly in three EMT markers (Supplementary Table S1 and Supplementary Figure S4). These results also agreed with our observations on rat preneoplastic cell lines (see Figure 1C, Section 2.1, and Supplementary Figure S1) and rat MM tumors (Figure 1C, Supplementary Figure S4, bottom 
graphs), except for vimentin, due to the fact that all four rat MM tumors presented a sarcomatoid morphology [17]. This role of S100A4 in human MM invasiveness is also consistent with the observation of a decreased survival probability for patients with renal cancer and high S100A4 expression (Supplementary Figure S5 [26]).

\subsection{S100A4 Increases with the Development Stage of MM Liver Metastases}

We previously identified important differences in invasiveness level and stroma composition between our three experimental models of rat invasive MM [17]. In particular, the most invasive, M5-T1, was characterized by the capacity to generate metastases in multiple secondary organs, especially the liver [27], as confirmed by MRI (magnetic resonance imaging) (Figure 3).

\section{$\mathbf{A}$}
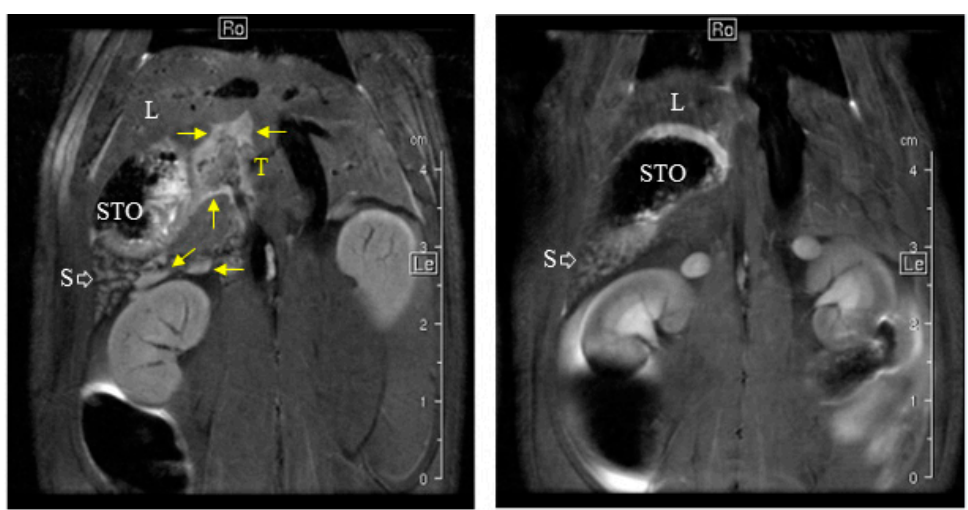

B
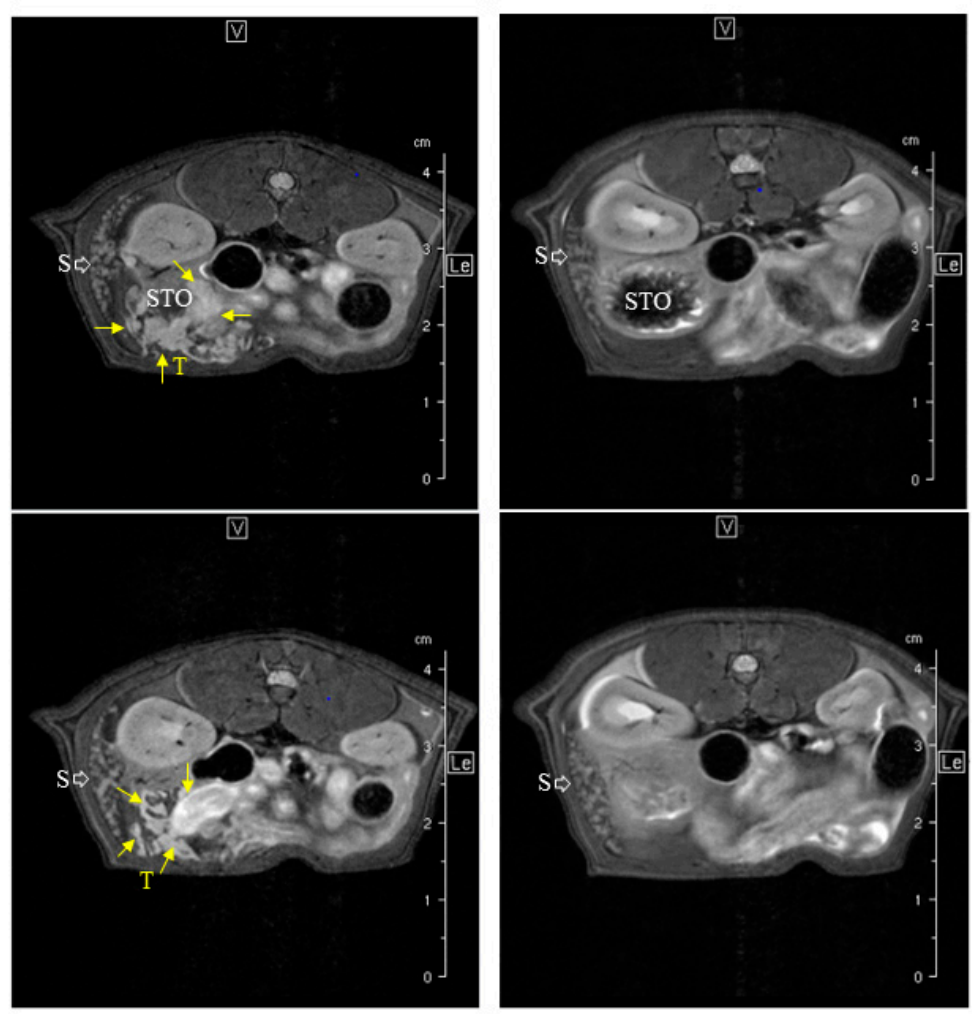

Figure 3. MRI-based staging of the M5-T1 MM model. M5-T1 tumor (T, and yellow arrows) was present as omental cakes and nodules attached to the stomach (STO) and spleen (S) on both coronal (A) and axial images (B). M5-T1 tumor was also characterized by the presence of metastatic tumor development into the liver parenchyma (L) and along the portal vein. Note the changes in volume and white pulp vs. red pulp signal intensity of the spleen in the tumor-bearing rat in comparison to normal rat spleen. 
We therefore wondered whether the level of S100A4 would change in liver metastases according to their development stage. For this purpose, M5-T1 liver metastases were collected from two groups of rats that differed in the number/extent of secondary organs affected by M5-T1 cell invasion. The first group (advanced stage) corresponded to rats with the initial stages of diaphragm invasion, preservation of the splenic capsule, no nodules infiltrating the peritoneum, and liver metastases of an average of $2.87 \mathrm{~mm}$ in diameter, without deep infiltration. The second group (final stage) was characterized by deep invasion of the diaphragm, portal space, and spleen, the presence of nodules infiltrating the peritoneum, and multiple, deep liver metastases of an average of $5.25 \mathrm{~mm}$ in diameter. Histological examination revealed two observations that characterized the final stage: the presence of multiple isolated M5-T1 cells deeply infiltrating the organ at distance from the tumor front, and evidence of alterations of the liver parenchyma architecture (Figure 4A, right column). In contrast, the advanced stage was characterized by the absence of these two elements (Figure 4A, left column). SWATH-MS analysis of the two groups of tumors showed that they differed by 148 proteins presenting significant differences in abundance (Figure 1A), 10 of which were also present on the list of 39 biomarkers established in Table 2. Interestingly, the most significant ratios were observed for S100A4 and two enzymes of the glycolysis pathway, triose phosphate isomerase (TPIS) and phosphoglycerate mutase 1 (PGAM1) (Figure 4B).

A

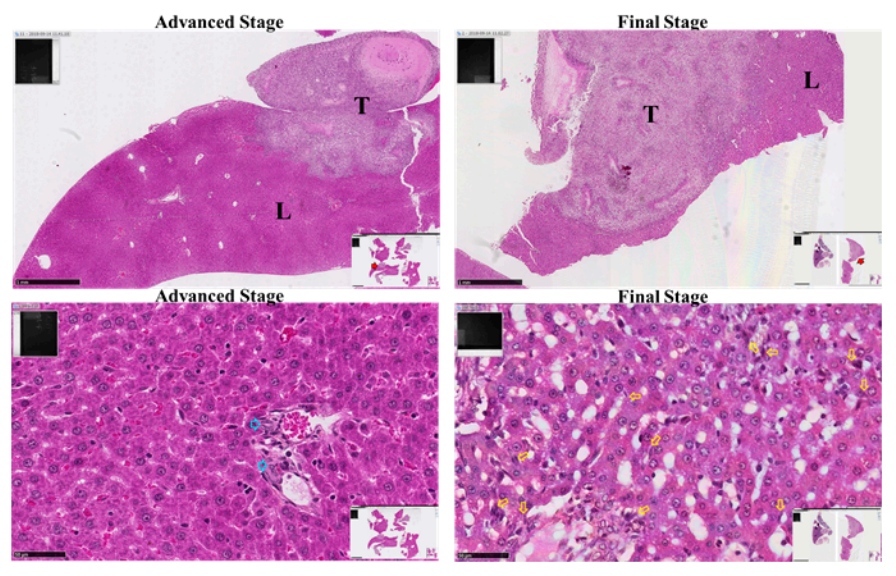

B

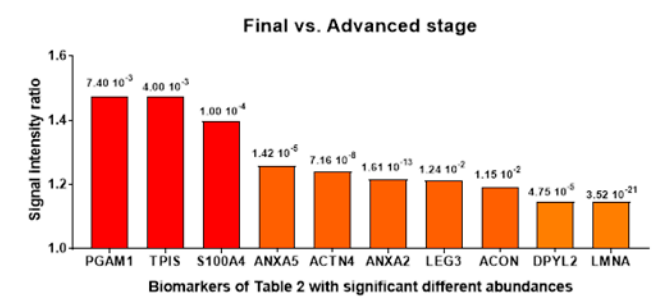

Figure 4. Comparison between liver metastases and primary tumor, M5-T1 tumor model. (A) Histological features of the two stages identified in the colonization of the liver by M5-T1 cells. Top rank, general views $(\times 25$, the scale bar represents $1 \mathrm{~mm})$ showing the extent of tumor $(\mathrm{T})$ development within the liver tissue (L). Bottom rank, detailed views $(\times 400$, the scale bar represents $50 \mu \mathrm{m})$. The final stage was characterized by the presence of numerous isolated metastatic M5-T1 cells infiltrating the liver parenchyma (yellow arrows), in contrast to the advanced stage for which the tumor cells were only localized within the portal triad (blue arrows). (B) Proteomic analysis: Abundance ratios (final versus advanced stage) for the 11 biomarkers exhibiting significant differences $(p<0.05)$, and also found in the list of 39 biomarkers detailed in Table 2, $p$ values are indicated for each biomarker at the top of the bars.

\subsection{S100A4, Biomarker for Colonization of the Spleen by MM Tumor Cells}

We next determined which of the 39 biomarkers (Table 2) were detectable by SWATH-MS analysis and to what extent their abundances were impacted when colonization by the most invasive M5-T1 cells extended to a central lymphoid organ, the spleen (Figure 1A), in comparison with control rats, 
and how these changes evolved within the different tumor progression stages. This experiment was justified by the observation of changes in MR images (Figure 3), and histology of the spleen (Figure 5) in tumor-bearing rats relative to normal rats.

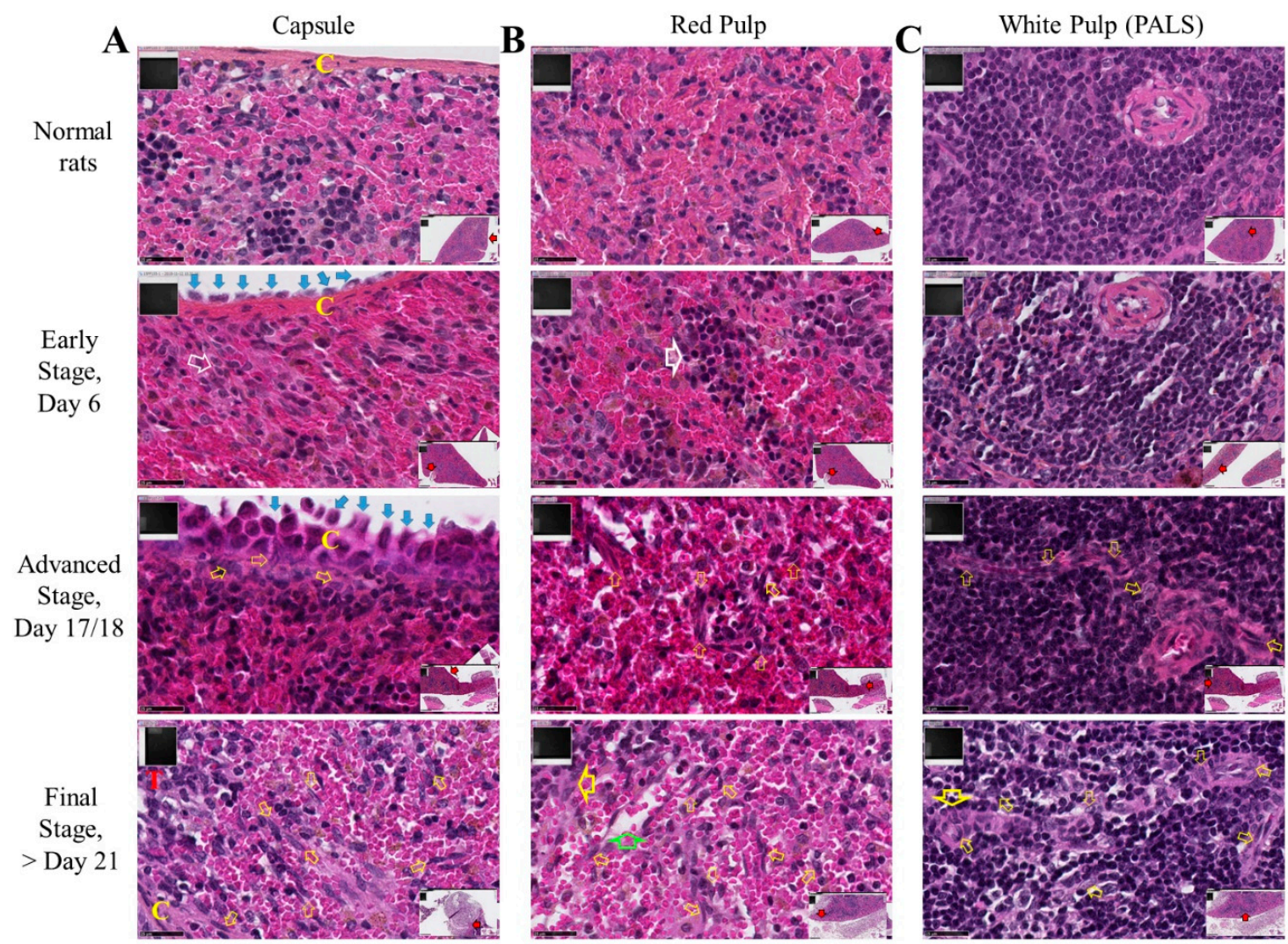

Figure 5. Spleen colonization by M5-T1 cells. High magnification views of the successive stages $(\times 800)$. Scale bars represent $25 \mu \mathrm{m}$, inserts showing general views $(\times 25)$. (A) Invasion of the capsule (C, in yellow). The open white arrow shows clustering of reticular cells. Open yellow arrows indicate M5-T1 tumor cells crossing the capsule or present in the red pulp. Vicinal tumor, T in red. (B) Red pulp. Early stage: the architecture of the red pulp is preserved, large open white arrow indicating clusters of lymphoid cells on the tumor side attached to the spleen surface. Advanced stage and onwards: open yellow arrows indicate numerous tumor cells actively moving inside the red pulp. Final stage: the large green arrow shows empty spaces, attesting a decrease in the density of normal cells. The large yellow arrow indicates clusters of lymphoid and tumor cells. (C) White pulp, periarteriolar lymphoid sheath (PALS). Early stage: the architecture of the follicle is preserved on this cross-section of the central artery. Advanced stage: open yellow arrows indicate tumor cells penetrating the PALS on this longitudinal section of the central artery. Final stage: tumor cells present everywhere following the destruction of the stromal framework of reticular fibers.

Histological examination at high magnification $(\times 800)$ of a set of paraformaldehyde-fixed paraffin-embedded organs and tissues (liver, pancreas, spleen, kidney, diaphragm, peritoneal wall, lymph nodes, colon, duodenum, omentum, and adipose tissue) collected from 20 M5-T1 tumor-bearing rats at different stages of progression allowed the localization and morphological features of colonizing tumor cells to be determined. The typical features of M5-T1 metastatic cells colonizing different organs are shown in Supplementary Figure S6.

Next, histological examination of spleen sections from the group of M5-T1 tumor-bearing rats allowed us to identify three different stages of tumor progression according to the presence of tumor cells attached to/crossing the capsule (Figure 5A), and composition/morphological features of cells present in the red pulp (Figure 5B) or periarteriolar lymphoid sheath (Figure 5C). Sections of 
paraffin-embedded spleens of $20 \mu \mathrm{m}$ thick from $10 \mathrm{M} 5$-T1 tumor-bearing rats and 10 control rats were prepared for SWATH-MS analysis and biomarker abundances were compared. Table 3 summarizes the results, highlighting the significant changes observed for eight candidate biomarkers of pre-metastatic niche formation, and the fact that S100A4 showed the most significant increase in abundance as a consequence of tumor progression (Figure 6A). Comparison of the abundances for other proteins of the S100 family demonstrated that five proteins were detected in the spleen tissue (S100A11, S100A6, S100A8, S100A9, and S100A4, in increasing order of abundance), S100A9 being the only one that increased (Figure 6B). In contrast, this protein was detected neither in cells nor in tumors, while changes were observed for S100A6, S100A10, and S100A11 but not for S100A8 (Supplementary Figure S7). Analysis of changes in abundance between the different stages for the eight markers identified above plus S100A9 revealed a comparable evolution for S100A4, Tubulin-specific chaperone A (TBCA), and, to a lesser extent Annexin A2 (ANXA2), the former still being the most sensitive to invasion by M5-T1 tumor cells (Figure 6C).

Table 3. Abundances of candidate biomarkers of tumor cell invasiveness in the spleens of rats with M5-T1 tumors relative to the spleens of control rats.

\begin{tabular}{|c|c|c|}
\hline Code & Name & Rats with Tumors vs. Control Rats \\
\hline ACADL & Long-chain specific acyl-CoA dehydrogenase, mitochondrial & ns \\
\hline ACON & Aconitate hydratase, mitochondrial & ns \\
\hline ACTN4 & Alpha-actinin-4 & ns \\
\hline ANXA2 & Annexin A2 & $\uparrow$ \\
\hline ANXA5 & Annexin A5 & $\uparrow$ \\
\hline ATPO & ATP synthase subunit $\mathrm{O}$, mitochondrial & ns \\
\hline BAF & Barrier-to-autointegration factor & ns \\
\hline DPYL2 & Dihydropyrimidinase-related protein 2 & ns \\
\hline EDF1 & Endothelial differentiation-related factor 1 & nd \\
\hline EMAL2 & Echinoderm microtubule-associated protein-like 2 & ns \\
\hline FKB1A & Peptidyl-prolyl cis-trans isomerase FKBP1A & ns \\
\hline GSHR & Glutathione reductase & nd \\
\hline $\mathrm{H} 2 \mathrm{AJ}$ & Histone H2A.J & ns \\
\hline H31 & Histone H3.1 & ns \\
\hline HYOU1 & Hypoxia up-regulated protein 1 & ns \\
\hline ICAL & Calpastatin & ns \\
\hline IF6 & Eukaryotic translation initiation factor 6 & ns \\
\hline LMNA & Prelamin-A/C & $(\uparrow) p=0.05103$ \\
\hline LUZP1 & Leucine zipper protein 1 & ns \\
\hline MOES & Moesin & ns \\
\hline MYH10 & Myosin-10 & ns \\
\hline NCAM1 & Neural cell adhesion molecule 1 & nd \\
\hline NDKB & Nucleoside diphosphate kinase B & $(\uparrow) p=0.06241$ \\
\hline NDRG1 & Protein NDRG1 & $\uparrow$ \\
\hline OPLA & 5-oxoprolinase & $\uparrow$ \\
\hline PA1B2 & Platelet-activating factor acetylhydrolase IB subunit beta & ns \\
\hline PHB & Prohibitin & ns \\
\hline PRDX3 & Thioredoxin-dependent peroxide reductase, mitochondrial & ns \\
\hline RLA0 & $60 \mathrm{~S}$ acidic ribosomal protein $\mathrm{P0}$ & $\downarrow$ \\
\hline RTCB & tRNA-splicing ligase RtcB homolog & ns \\
\hline S10A4 & Protein S100-A4 & $\uparrow$ \\
\hline SEPT2 & Septin-2 & ns \\
\hline STABP & STAM-binding protein OS=Rattus norvegicus & ns \\
\hline
\end{tabular}


Table 3. Cont.

\begin{tabular}{ccc}
\hline Code & Name & Rats with Tumors vs. Control Rats \\
\hline TBCA & Tubulin-specific chaperone A & $\uparrow$ \\
\hline TBG1 & Tubulin gamma-1 chain & $\uparrow$ \\
\hline TCTP & Translationally-controlled tumor protein & $\mathrm{ns}$ \\
\hline TYB10 & Thymosin beta-10 & $(\downarrow) p=0.05936$ \\
\hline UB2V2 & Ubiquitin-conjugating enzyme E2 variant 2 & $\mathrm{ns}$ \\
\hline UGGG1 & UDP-glucose:glycoprotein glucosyltransferase 1 & $\mathrm{ns}$ \\
\hline
\end{tabular}

The eight main proteins of interest are highlighted with arrows indicating the direction of change. Three additional proteins of interest showed strong tendencies $(0.050<p<0.063)$. ns $=$ differences not significant $(p>0.07)$, nd $=$ proteins not detected in spleen samples, yellow $=$ increase, green $=$ decrease .

$\mathbf{A}$

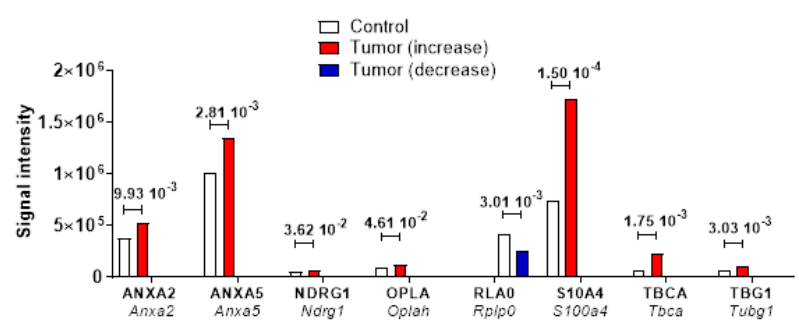

B

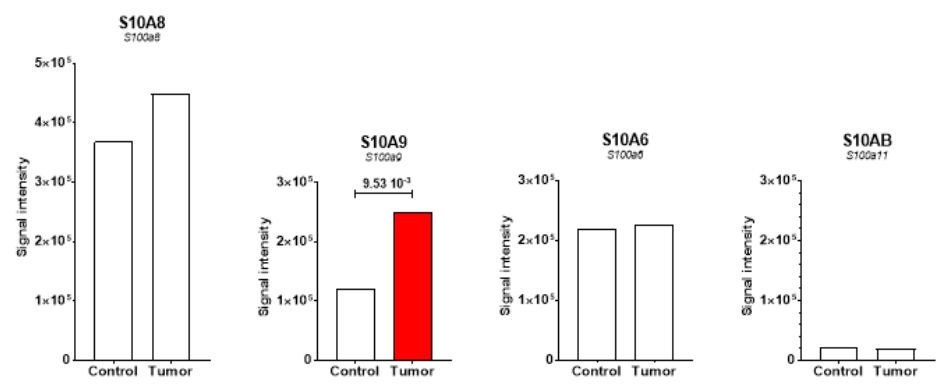

C
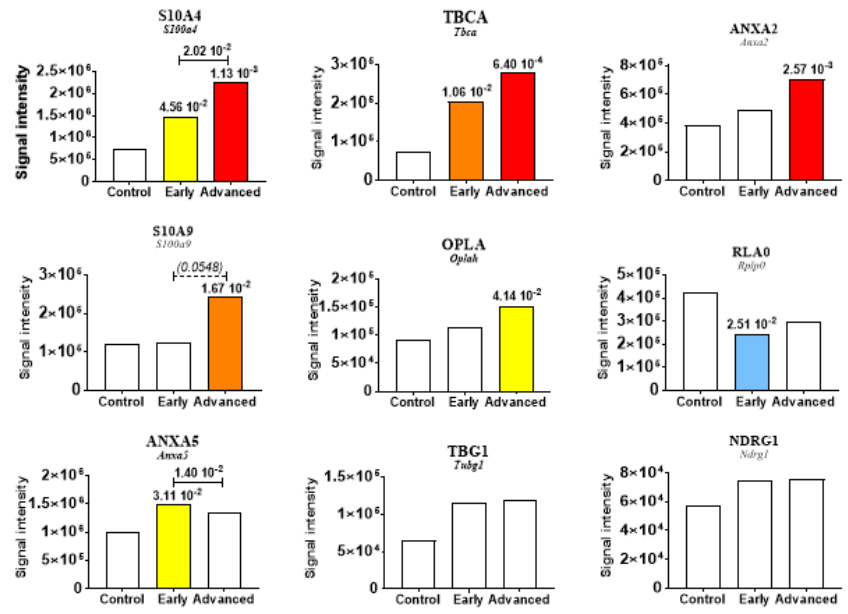

Figure 6. Biomarkers of spleen colonization. Changes in protein abundances in the spleen tissue of rats with M5-T1 mesothelioma (Tumor) in comparison with control rats (Control). (A) Eight potential biomarkers showing significant differences. Proteins detected in the spleen from the 39 proteins listed in Table 2. (B) Other S100 proteins detected in spleen. (C) Evolution of the eight biomarkers plus S100A9 according to the stage of M5-T1 mesothelioma development. "Early" and "Advanced" correspond to the spleens of tumor-bearing rats. Blank bars correspond to the absence of significant differences between groups. 


\section{Discussion}

A characteristic feature of malignant mesothelioma is that it is a good base for studying both EMT and invasiveness, as is it characterized by the concomitant presence of epithelioid and sarcomatoid features [12]. To date, diagnosis, prognosis, and therapy are still challenging for this aggressive cancer, reliable predictive biomarkers are lacking, and a personalized therapeutic concept is urgently needed [28]. This work emphasized the value of S100A4, a potential biomarker of interest involved in all steps of experimental MM pathogenesis, which could contribute to fulfilling these aims. Moreover, the methodology and preclinical models that we used allowed us to analyze in parallel the additional value of some other proteins, whose interrelationships with S100A4 raise specific questions.

The pertinence of several MM biomarkers has been analyzed over the last decade; however, for diagnostic purposes, none are satisfactory, although many are under investigation [29,30]. Sudo et al. previously emphasized the fact that while the pathological diagnostic markers for epithelioid MM were established, no adequate marker for sarcomatoid MM was found, when they identified AHNAK as a potential marker 5 years ago [31]. Although AHNAK mesothelioma-associated gene mutation was recently found in a rare type of human MM, its role in MM pathogenesis is still under investigation [32]. Interestingly, our results obtained on experimental cell lines and tumor models of sarcomatoid MM in rats corroborated the work of Fassina et al. on a collection of 109 malignant mesothelioma specimens from patients who observed a progressive increase in S100A4 immunohistochemical staining from epithelioid to biphasic and sarcomatoid subtypes [33]. This elevation of S100A4 is also consistent with its overexpression in different types of metastatic cancer [1], and its established value as an indicator of poor prognosis and a therapeutic target for colon cancer [34].

Several studies have already been dedicated to proteomic analyses of different types of MM samples, cell lines, sera, pleural effusions, or surgically resected materials from patients. However, few have provided quantifications of biomarkers of interest identified in each situation. Among them, Ziegler et al. used cell surface capturing (CSC) technology to identify biomarkers which allowed them to differentiate between the human pleural MM cell line ZL55 and lung adenocarcinoma (ADCA) Calu-3, and they identified Thy-1/CD90 as a candidate [35]. Mundt et al. applied another technique for distinguishing pleural effusions in patients with MM, ADCA, or benign mesotheliosis, identifying galectin-1 as a diagnostic biomarker [36]. Subsequently, 142 differentially expressed proteins were identified by comparing epithelioid and sarcomatoid pleural MM samples [37]. White et al. recently extended this work using the new technology SWATH-MS, finding that protein S100A6 was upregulated 2.5-fold and 2.1-fold in MM versus ADCA and MM versus benign reactive effusions, respectively [38]. This finding is interesting as it corroborates our data on the increased abundance of S100A6 that accompanied the increased abundance of S100A4 in all three invasive MM tumors versus the non-invasive MM tumor. Finally, in the work of Creaney et al., where six human MM cell lines were compared against three primary mesothelial cell culture preparations using iTRAQ ${ }^{\circledR}$ mass spectrometry (isobaric tag for relativeand absolute quantitation) [39], two upregulated proteins were also found in our data, annexin A2 and prelamin-A/C.

In our study, the changes in S100A4 within the different categories of preneoplastic rat mesothelial cell lines were consistent with our observation that Hif1a expression increases between PNsarc2 vs. PNsarc1. The presence of HIF-1 could also explain the parallel rise in Vegfa expression in these cell lines, and the highest invasiveness of M5-T1 tumor [17], in agreement with the statement that its presence in tumor microenvironment could foster the expression of VEGF, among others [5]. The relationship between HIF-1/2 $\alpha$ and EMT is now clearly demonstrated [40], and the links between HIF-1 $\alpha$ expression, EMT, and generation of distant metastases, for example in advanced lung cancer, are established [41]. However, we established for the first time a link between the increase in S100A4 in the context of hypoxia and EMT in the case of preneoplastic mesothelial cells. To summarize, in line with previous observations that in normal and benign lesions, S100A4 is restricted to a few stromal fibroblasts and inflammatory cells [42], while both tumor and stromal cells secrete the protein in malignant tumors [42,43], we observed a continuous rise in S100A4 from subnormal, epithelioid, sarcomatoid 
non-tumorigenic mesothelial cells to MM cell lines. The increased abundance of this protein in invasive versus non-invasive MM cell lines and invasive versus non-invasive MM tumors was consistent with reports of its higher expression in the peripheral leading edge of breast cancer [43], non-small-cell lung cancer (NSCLC) [44], and gain of S100A4/loss of membrane E-cadherin in cervical cancer with an unfavorable prognosis [8]. The parallel between S100A4 and fibronectin is also of interest, as the continuous increase in protein abundance between subgroups Sbnl, PNep, and PNint, and the difference between sarcomatoid and epithelioid preneoplastic rat mesothelial cell lines suggest a relationship with the Wnt signaling pathway [45]. In our study, this rise in fibronectin also observed within rat MM tumors, previously reported to be associated with increasing invasiveness [17], was comparable to that observed in the sarcomatoid vs. epithelioid human MM tumors, in good agreement with the role of Wnt signaling pathway in NSCLC [46]. Regarding the value of S100A4 compared to other known prognostic markers such as p16 and PD-L1, we previously showed a decreased relative expression of $C d k n 2 a$ (p16) in neoplastic relative to preneoplastic rat cell lines and in human MM cell lines relative to normal mesothelial cells [18]. Interestingly, our findings on MM were consistent with the data of Pezzuto et al., who found altered expression of p16 in patients with NSCLC, indicating that p16 could be a potential marker of lung cancer evolution and aggressiveness, unlike PD-L1 and Ki-67 which did not affect overall survival [47]. Other findings by Chapel et al. in a cohort of patients with malignant pleural mesothelioma confirmed that tumor PD-L1 expression was not significantly associated with overall survival [48]. Overall, these findings could contribute to improve the potential utility of invasiveness biomarkers, beside the role of mesothelin, osteopontin, fibulin-3, hyaluronic acid, VEGF, and MPF in the diagnosis and prognosis of MM [49].

Among the list of markers of tumorigenesis/invasiveness that were previously identified, eight proteins evolved in a similar way in the spleens of tumor-bearing rats as in control rats, of which S100A4 was the most effected. Besides the dramatic changes observed for S100A4, S100A9 was the only member of this family that was detected neither in cells nor in tumors. As this protein belongs to the list of molecular components that promote pre-metastatic niche formation [2], acting as a chemoattractant for macrophages and hematopoietic progenitor cells accumulating in pre-metastatic lungs [50,51], the changes observed could be explained by variations in cellular composition of this central lymphoid organ. With S100A8, they represent damage-associated molecular pattern molecules (DAMPs) [52], producing a complex that promotes cancer development and invasion [53], a promising target for the development of new strategies of treatment [54]. S100A4 and S100A9 show common molecular interactions [55], both being associated with inflammation and in vivo tumor progression, reducing overall survival for the patient [3]. However, the fact that S100A9 increased while S100A8 remained unchanged suggests an imbalance between the homodimer and heterodimer/heterotetramer forms mentioned in the literature [56], a finding emphasized by the lack of significant changes for S100A8 between preneoplastic and neoplastic cell lines, and between invasive and non-invasive neoplastic cell lines. The parallel evolution of TBCA and ANXA2 also raises additional questions. TBCA is a member of a family of proteins that act at different levels of a folding pathway to generate tubulin heterodimers involved in many cellular functions. As two independent studies have reported a role for these chaperones in the sensitivity/resistance to treatment of different types of cancer $[57,58]$, the similarity of S100A4 and TBCA profiles in rat spleen in the context of MM progression is intriguing. The additional data on ANXA2 finally suggest that markers of communication between cells/intracellular transport, cell motility, and cellular architecture are closely interconnected, especially in the more advanced stages, highlighting the key role of the S100A4/annexin A2 interaction [59].

Other than S100A4, our study also led us to identify several other potential markers of interest for MM, including annexin A5 [60], as its serum level in patients with colon cancer is related to lymph node metastasis and tumor grades [61], while investigations of its role and action in hepatocarcinoma malignancy has revealed that its knockdown suppressed the expression of key molecules in the integrin and MEK-ERK pathways (mitogen-activated protein kinases-extracellular signal-regulated kinases) [62]. Regarding lamin A/C, Kim et al. demonstrated that it forms a perinuclear apical actin 
cap, resisting nuclear deformation in response to physiological mechanical stresses [63]. Interestingly, the continuous rise in LMNA in F4-T2, F5-T1, and M5-T1 tumors is consistent with an increased tumor invasiveness [17] and the involvement of EMT at the invasive tumor front [64]. The parallel increase in H2A.J also corroborates the findings of Taheri et al., showing that the mobility of lamin A and histone H2A are interconnected in the nucleus [65], while H2A.J plays a central role in senescent cells with persistent DNA damage and in the expression of inflammatory genes that contribute to the senescent-associated secretory phenotype (SASP) [66].

\section{Materials and Methods}

\subsection{Biocollection of F344 Rat Mesothelial Cell Lines}

The rat mesothelial biocollection of cell lines was established in 2011 from a group of 33 F344 rats, which received an intraperitoneal inoculation of $10 \mathrm{mg}$ crocidolite fibers (UICC analytical sample, ref. 02704A, Neyco, Paris, France) at 8 weeks of age. The 22 preneoplastic and 4 neoplastic cell lines used in this study were obtained from individual rats from 136 to 415 days after induction, as previously described [17], and their classification is summarized in Table 1. Cell lines were grown in an RPMI 1640 medium, supplemented with 10\% heat-inactivated fetal bovine serum, $2 \mathrm{mM}$ L-glutamine, $100 \mathrm{U} / \mathrm{mL}$ penicillin, and $100 \mu \mathrm{g} / \mathrm{mL}$ streptomycin (all reagents from Gibco Life Technologies Limited, Paisley, UK) at $37^{\circ} \mathrm{C}$ in a $5 \% \mathrm{CO}_{2}$ atmosphere. Cells were collected from preconfluent $75 \mathrm{~cm}^{2} \mathrm{flasks}$ of each cell line and cell pellets of $2 \times 10^{6}$ cells were used for SWATH-MS proteomic analysis after being washed in PBS (phosphate-buffered saline) buffer.

\subsection{Total RNA Isolation and Real-Time PCR}

To complete our previous classification of the biocollection of rat mesothelial cell lines, PCR reactions were performed as previously described [18] for 15 additional genes for the nine cell lines representing the PNsarc group of preneoplastic cells (Table 1)_Il6, Fgf2, Egf, Vegfa, Pdgfa, Fhit, Hif1a, Stat3, Erbb2, Nfkb1, Tnf, Il1b, Ccl5, Ccl7, and Ccl3. Each transcript level was normalized relative to the acidic ribosomal phosphoprotein P0 housekeeping gene (Rplp0), used as an internal standard.

\subsection{Malignant Mesothelioma Tumors}

Fischer F344 rats were purchased from Charles River Laboratories (L'Arbresle, France), and maintained under SPF status and standard conditions in the UTE-IRS UN animal facility of the University of Nantes in compliance with the European Union guidelines for the care and use of laboratory animals in research protocols (Agreement \#01257.03). All experiments were approved by the ethics committee for animal experiments of the Pays de la Loire Region, France (CEEA.2011.38 and CEEA.2013.7.). In order to follow the recommendations on the welfare and use of animals in cancer research, particular attention was given to incorporating the objectives of the 3Rs (replacement, reduction, and refinement) [67]. The four neoplastic cell lines (M5-T2, F4-T2, F5-T1, and M5-T1) were injected into syngeneic rats and tumors were collected and fixed as previously described [16,17]. The rats were anesthetized in an isoflurane chamber (Forene ${ }^{\circledR}$, Abbott, France) and euthanized with a rate of $30 \%$ volume displacement per minute of $\mathrm{CO}_{2}$ into their home cage.

\subsection{Sample Preparation for SWATH-MS Analysis}

The rat spectral library, DDA experiments, and peptide identification were performed as previously described (see Materials and Methods section in Reference [17]). The staging (Ki67 index) and histology features (infiltration atypia, blood vessel density, and $\mathrm{T}$ cell and macrophage counts) of the four different rat MM models were described in Figure 1, Tables 1 and 2 [17]. Paraffin-embedded sections of representative tumors, stained with hematoxylin-phloxine-saffron (HPS), were first examined to select areas of interest, and then all the corresponding areas were removed with a scalpel from five thicker $(20 \mu \mathrm{m})$ sections of the samples and collected in a microtube. Samples were deparaffinized 
with xylene, subjected to a succession of incubations in 100\%, 95\%, 70\% and 50\% ethanol baths followed by centrifugations, and finally dried in a SPD121P SpeedVac Concentrator. Cell pellets and dried deparaffinized tumor samples were treated with Rapigest ${ }^{\mathrm{TM}}$ SF Surfactant (Waters Corporation, Milford, MA, USA) and DTT $0.1 \mathrm{M}$ at $95^{\circ} \mathrm{C}$ for $90 \mathrm{~min}$ with continuous stirring (Thermomixer Comfort, Eppendorf), and then sonicated three times for $30 \mathrm{sec}$ (ultrasonic processor, model 75185, Bioblock Scientific, Illkirch, France). MMTS $200 \mathrm{mM}$ was then added for $10 \mathrm{~min}$ at $37^{\circ} \mathrm{C}$ with continuous stirring before being treated with trypsin w/ $\mathrm{CaCl}_{2}$ TPCK (P/N 4352157, AB Sciex Pte, Ltd., Framingham, MA, USA) overnight. After centrifugation, salts were removed using OASIS ${ }^{\circledR}$ HLB extraction cartridges (Waters SAS, St Quentin-en-Yvelynes, France.) before drying under SpeedVac. Peptide concentrations of the samples were finally determined using the Micro BCA ${ }^{\mathrm{TM}}$ protein assay kit (Thermofisher Scientific, St Herblain, France). For treatment with trypsin, desalting, and peptide analysis, ultrapure water (Purelab Option-Q, 18.2 M $\Omega . c m$, VWR International S.A.S., Fontenay-sous-Bois, France) was used during all procedures. See legends to Supplementary Table S1 and reference [68] for additional informations on sample preparation of human tumor samples.

\subsection{Relative Quantification by SWATH Acquisition and Statistical Analysis}

Each sample $(5 \mu \mathrm{g})$ was analyzed with LC-MS/MS equipment and a LC gradient to build the spectral library, but using a SWATH-MS acquisition method. The method consisted of repeating the whole gradient cycle, which corresponded to acquisition of 32 TOF (time of flight) MS/MS scans of overlapping sequential precursor isolation windows $(25 \mathrm{~m} / \mathrm{z}$ isolation width, $1 \mathrm{~m} / \mathrm{z}$ overlap, high sensitivity mode) covering the 400 to $1200 \mathrm{~m} / \mathrm{z}$ mass range, with a previous MS scan for each cycle. The accumulation time was $50 \mathrm{~ms}$ for the MS scan (from 400 to $1200 \mathrm{~m} / \mathrm{z}$ ) and $100 \mathrm{~ms}$ for the product ion scan $(230$ to $1500 \mathrm{~m} / \mathrm{z})$, thus giving a total cycle time of $3.5 \mathrm{sec}$.

Peak extraction of the SWATH data was performed using either the Spectronaut software (v. 8.0, Biognosys, Switzerland) or SWATH micro App embedded in Peak View (v. 2.0, AB Sciex Pte, Ltd., Framingham, MA, USA). SWATH data were processed with default settings in Spectronaut. Reference peptides from the iRT-kit (Biognosys) spiked into each sample were used to calibrate the retention time of extracted peptide peaks using Spectronaut. Peptide identification results were filtered with a q-value of $<1 \%$, excluding shared peptides. RT calibration was also performed based on iRT peptide elution profiles in PeakView using the SWATH App module (v. 2.0). After peak extraction with either Spectronaut or PeakView, the sum of MS2 ion peak areas of SWATH quantified peptides for individual proteins were exported to calculate the protein peak areas.

For the statistical analysis of the SWATH data set, peak extraction output data matrix from PeakView was imported into MarkerView (v. 2, Sciex) for data normalization and relative protein quantification. Proteins with a fold change $>1.5$ and statistical $p$-value $<0.05$ estimated by MarkerView were considered to be differentially expressed under different conditions.

\subsection{MRI-Based Staging of the M5-T1 MM Model}

Coronal and axial MR images of M5-T1-tumor bearing rats (in comparison with normal rats) were acquired at Day 15 after tumor challenge on a Biospec Avance III 70/20 MR scanner (Bruker Wissembourg, France) working at 7.0 T, equipped with a horizontal bore magnet, $120 \mathrm{~mm}$ diameter gradient system $(675 \mathrm{mT} / \mathrm{m})$, and transmitter/receiver $86 \mathrm{~mm}$ volume coil. Data were collected using ParaVision 6.0 software (Bruker, Wissembourg, France). A fast spin echo sequence was applied with following parameters to this end: TE (Echo Time) $=30 \mathrm{~ms}$, TR $\mathrm{min}=740 \mathrm{~ms}$ (respiratory triggering), four averages, echo train length $=4,60 \times 60 \mathrm{~mm}$ field of view, $256 \times 256$ matrix, nine slices with a thickness of $1 \mathrm{~mm}$ oriented either axially or sagittally.

\section{Conclusions}

In conclusion, these results showed that S100A4 was the only protein with a common increase in abundance in all the situations studied, highlighting a crucial role for this biomarker in the multistep 
MM pathogenesis process, including tumorigenesis, EMT, invasion, and colonization of host organs. Its relationships with members of the annexin family, and the dynamic interplay between lamins and chromatin, represent an interesting basis for future mechanistic studies.

Supplementary Materials: The following are available online at http://www.mdpi.com/2072-6694/12/4/939/s1, Figure S1: Comparative proteomic abundances of EMT markers in the different groups and subgroups of rat mesothelial cell lines, described in Table 1. Figure S2: Evolution of proteomic abundances for the 12 additional major candidate biomarkers (complement to S100A4 shown in Figure 1C). Figure S3: Sections of each human MM tumor histological subtype, stained with HPS. Figure S4: Proteomic abundances of protein S-100A4 and EMT markers in human MM tumor samples (data extracted from Supplementary Table S1). Figure S5: Illustration of the impact of protein S-100A4 expression on survival probability for patients with renal cancer (The human protein atlas/Pathology atlas). Figure S6: M5-T1 rat mesothelioma tumor cells invading secondary organs and tissues. Figure S7: Comparative abundances of additional S100 proteins detected in rat mesothelial cell lines and tumors. Table S1: Comparative SWATH-MS analysis of human pleural malignant mesotheliomas (sarcomatoid vs. epithelioid).

Author Contributions: D.L.P. and O.C. conceived the ideas, with an important intellectual contribution from J.G. and C.P. through complementary investigations. J.S.N. and D.L.P. conceived and designed all the experiments on cell lines tumors and tissues and analyzed the data. S.B., J.S.N. and D.L.P. conducted the histological analysis, and S.L. assisted with the in vivo experiments on rats. F.F. and D.L.P. performed MRI. B.N.-R. and P.B. provided important critical feedback, and assisted with the histological examination and analysis of complementary sources of data. D.L.P. drafted the manuscript with the support of J.S.N., J.G., C.P., A.B., M.G., B.N.-R., P.B., V.V., C.G. and O.C., who therefore shaped the research content for the final manuscript. All authors agreed with the submission in its present form. All authors have read and agreed to the published version of the manuscript.

Funding: This research was funded by La Ligue Contre le Cancer (Ligue inter-régionale du Grand-Ouest), grant $\mathrm{N}^{\circ} \mathrm{R} 17029 \mathrm{NN}$.

Acknowledgments: This study was conducted with the support of the French National Health and Medical Research Institute (INSERM), the Ligue contre le Cancer (Ligue inter-régionale du Grand Ouest, comités 16, 29, 44, 72), and the Fondation pour la Recherche Médicale (FRM). We are most grateful to Floriane Briand and Sophie Deshayes (CRCINA, team 4, for PCRs), Marine Malloci (MicroPICell facility, Nantes University, for preparation of histological sections) and the PRISM core facility (Rennes-Angers, France) for their excellent technical support.

Conflicts of Interest: The authors declare that they have no competing interests.

Availability of Data and Materials: All informations about the data and materials used are included in the article or the accompanying additional files.

\section{References}

1. Fei, F.; Qu, J.; Zhang, M.; Li, Y.; Zhang, S. S100A4 in cancer progression and metastasis: A systematic review. Oncotarget 2017, 8, 73219-73239. [CrossRef]

2. Liu, Y.; Cao, X. Characteristics and significance of the pre-metastatic niche. Cancer Cell 2016, 30, 668-681. [CrossRef]

3. Hansen, M.T.; Forst, B.; Cremers, N.; Quagliata, L.; Ambartsumian, N.; Grum-Schwensen, B.; Klingelhöffer, J.; Abdul-Al, A.; Hermann, P.; Osterland, M.; et al. A link between inflammation and metastasis: Serum amyloid A1 and A3 induce metastasis, and are targets of metastasis-inducing S100A4. Oncogene 2015, 34, 424-435. [CrossRef]

4. Chaffer, C.L.; San Juan, B.P.; Lim, E.; Weinberg, R.A. EMT, cell plasticity and metastasis. Cancer Metastasis Rev. 2016, 35, 645-654.

5. Pezzuto, A.; Carico, E. Role of HIF-1 in cancer progression: Novel insights. A review. Curr. Mol. Med. 2018, 18, 343-351. [CrossRef]

6. Bresnick, A.R.; Weber, D.J.; Zimmer, D.B. S100 proteins in cancer. Nat. Rev. Cancer 2015, 15, 96-109. [CrossRef]

7. Amatangelo, M.D.; Goodyear, S.; Varma, D.; Stearns, M.E. C-Myc expression and MEK1-induced Erk2 nuclear localization are required for TGF-beta induced epithelial-mesenchymal transition and invasion in prostate cancer. Carcinogenesis 2012, 33, 1965-1975. [CrossRef]

8. Liu, M.; Liu, J.; Yang, B.; Gao, X.; Gao, L.L.; Kong, Q.Y.; Zhang, P.; Li, H. Inversed expression patterns of S100A4 and E-cadherin in cervical cancers: Implication in epithelial-mesenchymal transition. Anat. Rec. 2017, 300, 2184-2191. [CrossRef] 
9. Chow, K.-H.; Park, H.J.; George, J.; Yamamoto, K.; Gallup, A.D.; Graber, J.H.; Chen, Y.; Jiang, W.; Steindler, D.A.; Neilson, E.G.; et al. S100A4 is a biomarker and regulator of glioma stem cells that is critical for mesenchymal transition in glioblastoma. Cancer Res. 2017, 77, 5360-5373. [CrossRef]

10. Weidenfeld, K.; Barkan, D. EMT and stemness in tumor dormancy and outgrowth: Are they intertwined processes? Front. Oncol. 2018, 8, 381. [CrossRef]

11. Klebe, S.; Brownlee, N.A.; Mahar, A.; Burchette, J.L.; Sporn, T.A.; Vollmer, R.T.; Roggli, V.L. Sarcomatoid mesothelioma: A clinical-pathological correlation of 326 cases. Mod. Pathol. 2010, 23, 470-479. [CrossRef]

12. Pinton, G.; Manente, A.G.; Tavian, D.; Moro, L.; Mutti, L. Therapies currently in phase II trials for malignant pleural mesothelioma. Exp. Opin. Investig. Drugs 2013, 22, 1255-1263. [CrossRef]

13. Minnema-Luiting, J.; Vroman, H.; Aerts, J.; Cornelissen, R. Heterogeneity in immune cell content in malignant pleural mesothelioma. Int. J. Mol. Sci. 2018, 19, 1041. [CrossRef] [PubMed]

14. Bonelli, M.A.; Fumarola, C.; La Monica, S.; Alfieri, R. New therapeutic strategies for malignant pleural mesothelioma. Biochem. Pharmacol. 2017, 123, 8-18. [CrossRef] [PubMed]

15. Marchevsky, A.M. Application of immunohistochemistry to the diagnosis of malignant mesothelioma. Arch. Pathol. Lab. Med. 2008, 132, 397-401.

16. Chen, Z.; Gaudino, G.; Pass, H.I.; Carbone, M.; Yang, H. Diagnostic and prognostic biomarkers for malignant mesothelioma: An update. Trans. Lung Cancer Res. 2017, 6, 259-269. [CrossRef]

17. Nader, J.S.; Abadie, J.; Deshayes, S.; Boissard, A.; Blandin, S.; Blanquart, C.; Boisgerault, N.; Coqueret, O.; Guette, C.; Grégoire, M.; et al. Characterization of increasing stages of invasiveness identifies stromal/cancer cell crosstalk in rat models of mesothelioma. Oncotarget 2018, 9, 16311-16329. [CrossRef]

18. Roulois, D.; Deshayes, S.; Guilly, M.-N.; Nader, J.S.; Liddell, C.; Robard, M.; Hulin, P.; Ouacher, A.; Le Martelot, V.; Fonteneau, J.F.; et al. Characterization of preneoplastic and neoplastic rat mesothelial cell lines: The involvement of TETs, DNMTs, and 5-hydroxymethylcytosine. Oncotarget 2016, 7, 34664-34687. [CrossRef]

19. Hoenerhoff, M.J.; Hong, H.H.; Ton, T.-V.; Lahousse, S.A.; Sills, R.C. A review of the molecular mechanisms of chemically-induced neoplasia in rat and mouse models in National Toxicology Program bioassays and their relevance to human cancer. Toxicol. Pathol. 2009, 37, 835-848. [CrossRef]

20. Van Nimwegen, M.J.; Verkoeijen, S.; Kuppen, P.J.K.; Velthuis, J.H.L.; van de Water, B. An improved method to study NK-independent mechanisms of MTLn3 breast cancer lung metastasis. Clin. Exp. Metastasis 2007, 24, 379-387. [CrossRef]

21. Liao, A.; Broeg, K.; Fox, T.; Tan, S.-F.; Watters, R.; Shah, M.V.; Zhang, L.Q.; Li, Y.; Ryland, L.; Yang, J.; et al. Therapeutic efficacy of FTY720 in a rat model of NK-cell leukemia. Blood 2011, 118, 2793-2800. [CrossRef]

22. Mangraviti, A.; Raghavan, T.; Volpin, F.; Skuli, D.; Gullotti, D.; Zhou, J.; Asnaghi, L.; Sankey, E.; Liu, A.; Wang, Y.; et al. HIF-1-targeting acriflavine provides long term survival and radiological tumor response in brain cancer therapy. Sci. Rep. 2017, 7, 14978. [CrossRef]

23. Zeisberg, M.; Neilson, E.G. Biomarkers of epithelial-mesenchymal transitions. J. Clin. Investig. 2009, 119, 1429-1437. [CrossRef]

24. Kim, M.-C.; Cui, F.-J.; Kim, Y. Hydrogen peroxide promotes epithelial to mesenchymal transition and stemness in human malignant mesothelioma cells. Asian Pac. J. Cancer Prev. 2013, 14, 3625-3630. [CrossRef]

25. Briand, F.; Nader, J.; Deshayes, S.; Grégoire, M.; Pouliquen, D.L. Differential expression of Hif1a, growth factors and cytokines related to EMT in an experimental biocollection of rat preneoplastic mesothelial cell lines. In Proceedings of the 8th International Meeting on Epithelial-Mesenchymal Transition, Houston, TX, USA, 7-10 December 2017. TEMTIA and Metastasis Research Center, Dept of Cancer Biology, MD Anderson Cancer Center, Abstract \#52.

26. The Human Protein Atlas, Version: 19.3, Updated 2020-03-06. Royal Institute of Technology, UU, Science for Life Laboratory, Sweden. Available online: https:/www.proteinatlas.org/ENSG00000196154-S100A4/ pathology/renal+cancer (accessed on 31 March 2020).

27. Pouliquen, D.L.; Nawrocki-Raby, B.; Nader, J.; Blandin, S.; Robard, M.; Birembaut, P.; Grégoire, M. Evaluation of intracavitary administration of curcumin for the treatment of sarcomatoid mesothelioma. Oncotarget 2017, 8, 57552-57573. [CrossRef]

28. Guazzelli, A.; Meysami, P.; Bakker, E.; Bonanni, E.; Demonacos, C.; Krstic-Demonacos, M.; Mutti, L. What can independent research for mesothelioma achieve to treat this orphan disease? Exp. Opin. Investig. Drugs 2019, 28, 719-732. [CrossRef] 
29. Panou, V.; Vyberg, M.; Weinreich, U.M.; Meristoudis, C.; Falkmer, U.G.; Røe, O.D. The established and future biomarkers of malignant pleural mesothelioma. Cancer Treat. Rev. 2015, 41, 486-495. [CrossRef]

30. Cristaudo, A.; Bonotti, A.; Guglielmi, G.; Fallahi, P.; Foddis, R. Serum mesothelin and other biomarkers: What have we learned in the last decades? J. Thorac. Dis. 2018, 10, S353-S359. [CrossRef]

31. Sudo, H.; Tsuji, A.B.; Sugyo, A.; Abe, M.; Hino, O.; Saga, T. AHNAK is highly expressed and plays a key role in cell migration and invasion in mesothelioma. Int. J. Oncol. 2014, 44, 530-538. [CrossRef]

32. Zhang, S.; Zhang, Q.; Sun, Q.; Tang, J.; Chen, J.; Ji, N.; Zheng, Y.; Fang, F.; Lei, W.; Li, P.; et al. Genome evolution analysis of recurrent testicular malignant mesothelioma by whole-genome sequencing. Cell Physiol. Biochem. 2018, 45, 163-174. [CrossRef]

33. Fassina, A.; Cappellesso, R.; Guzzardo, V.; Dalla Via, L.; Piccolo, S.; Ventura, L.; Fassan, M. Epithelial-mesenchymal transition in malignant mesothelioma. Mod. Pathol. 2012, 25, 86-99. [CrossRef]

34. Destek, S.; Gul, V.O. S100A4 may be a good prognostic marker and a therapeutic target for colon cancer. J. Oncol. 2018, 1828791. [CrossRef] [PubMed]

35. Ziegler, A.; Cerciello, F.; Bigosch, C.; Bausch-Fluck, D.; Felley-Bosco, E.; Ossola, R.; Soltermann, A.; Stahel, R.A.; Wollscheid, B. Proteomic surfaceome analysis of mesothelioma. Lung Cancer 2012, 75, 189-196. [CrossRef] [PubMed]

36. Mundt, F.; Johansson, H.J.; Forshed, J.; Arslan, S.; Metintas, M.; Dobra, K.; Lehtiö, J.; Hjerpe, A. Proteome screening of pleural effusions identifies galectin 1 as a diagnostic biomarker and highlights several prognostic biomarkers for malignant mesothelioma. Mol. Cell. Proteom. 2014, 13, 701-715. [CrossRef] [PubMed]

37. Grosserueschkamp, F.; Bracht, T.; Diehl, H.; Kuepper, C.; Ahrens, M.; Kallenbach-Thieltges, A.; Mosig, A.; Eisenacher, M.; Marcus, K.; Behrens, T.; et al. Spatial and molecular resolution of diffuse malignant mesothelioma heterogeneity by integrating label-free FTIR imaging, laser capture microdissection and proteomics. Sci. Rep. 2017, 7, 44829. [CrossRef]

38. White, R.; Pulford, E.; Elliot, D.J.; Thurgood, L.A.; Klebe, S. Quantitative mass spectrometry to identify protein markers for diagnosis of malignant pleural mesothelioma. J. Proteom. 2019, 192, 374-382.

39. Creaney, J.; Dick, I.M.; Leon, J.S.; Robinson, B.W.S. A proteomic analysis of the malignant mesothelioma secretome using iTRAQ. Cancer Genom. Proteom. 2017, 14, 103-118.

40. Yang, H.; Geng, Y.-H.; Wang, P.; Zhou, Y.-T.; Yang, H.; Huo, Y.-F.; Zhang, H.-Q.; Li, Y.; He, H.-Y.; Tian, X.-X.; et al. Extracellular ATP promotes breast cancer invasion and Epithelial-Mesenchymal Transition via Hypoxia-inducible factor $2 \alpha$ signaling. Cancer Sci. 2019, 110, 2456-2470. [CrossRef]

41. Pezzuto, A.; Perrone, G.; Orlando, N.; Citarella, F.; Ciccozzi, M.; Scarlata, S.; Tonini, G. A close relationship between HIF-1 $\alpha$ expression and bone metastases in advanced NSCLC, a retrospective analysis. Oncotarget 2019, 10, 7071-7079.

42. Yoshimura, H.; Otsuka, A.; Michishita, M.; Yamamoto, M.; Ashizawa, M.; Zushi, M.; Moriya, M.; Azakami, D.; Ochiai, K.; Matsuda, Y.; et al. Expression and roles of S100A4 in anaplastic cells of canine mammary carcinomas. Vet. Pathol. 2019, 56, 389-398. [CrossRef]

43. Lukanidin, E.; Sleeman, J.P. Buiding the niche: The role of the S100 proteins in metastatic growth. Semin. Cancer Biol. 2012, 22, 216-225. [CrossRef]

44. Mahmood, M.Q.; Ward, C.; Muller, H.K.; Sohal, S.S.; Walters, E.H. Epithelial mesenchymal transition (EMT) and non-small cell lung cancer (NSCLC): A mutual association with airway disease. Mod. Oncol. 2017, $34,45$. [CrossRef]

45. Gradl, D.; Kühl, M.; Wedlich, D. The Wnt/Wg signal transducer-catenin controls fibronectin expression. Mol. Cell. Biol. 1999, 19, 5576-5587. [CrossRef]

46. Stewart, D.J. Wnt signaling pathway in non-small cell lung cancer. J. Natl. Cancer Inst. 2014, 106, djt356. [CrossRef]

47. Pezzuto, A.; Cappuzzo, F.; D’Arcangelo, M.; Ciccozzi, M.; Navarini, L.; Guerrini, S.; Ricci, A.; D'Ascanio, M.; Carico, E. Prognostic value of p16 protein in patients with surgically treated non-small cell lung cancer; relationship with Ki-67 and PD-L1. Anticancer Res. 2020, 40, 983-990. [CrossRef]

48. Chapel, D.B.; Stewart, R.; Furtado, L.V.; Husain, A.N.; Krausz, T.; Deftereos, G. Tumor PD-L1 expression in malignant pleural and peritoneal mesothelioma by Dako PD-L1 22C3 pharmDx and Dako PD-L1 28-8 pharmDx assays. Hum. Pathol. 2019, 87, 11-17. [CrossRef]

49. Arnold, D.T.; Maskell, N.A. Biomarkers in mesothelioma. Ann. Clin. Biochem. 2018, 55, 49-58. [CrossRef] 
50. Hiratsuka, S.; Watanabe, A.; Aburatani, H.; Maru, Y. Tumour-mediated upregulation of chemoattractants and recruitment of myeloid cells predetermines lung metastasis. Nat. Cell Biol. 2006, 8, 1369-1375. [CrossRef]

51. Hiratsuka, S.; Watanabe, A.; Sakurai, Y.; Akashi-Takamura, S.; Ishibashi, S.; Miyake, K.; Shibuya, M.; Akira, S.; Aburatani, H.; Maru, Y. The S100A8-serum amyloid A3-TLR4 paracrine cascade establishes a pre-metastatic phase. Nat. Cell Biol. 2008, 10, 1349-1355. [CrossRef]

52. Foell, D.; Wittkowski, H.; Vogl, T.; Roth, J. S100 proteins expressed in phagocytes: A novel group of damage-associated molecular pattern molecules. J. Leukoc. Biol. 2007, 81, 28-37. [CrossRef]

53. Shabani, F.; Farasat, A.; Mahdavi, M.; Gheibi, N. Calprotectin (S100A8/S100A9): A key protein between inflammation and cancer. Inflamm. Res. 2018, 67, 801-812. [CrossRef]

54. Leanderson, T.; Liberg, D.; Ivars, F. S100A9 as a pharmacological target molecule in inflammation and cancer. Endocr. Metab. Immune Disord. Drug Targets 2015, 15, 97-104. [CrossRef]

55. Björk, P.; Källberg, E.; Wellmar, U.; Riva, M.; Olsson, A.; He, Z.; Törngren, M.; Liberg, D.; Ivars, F.; Leanderson, T. Common interactions between S100A4 and S100A9 defined by a novel chemical probe. PLoS ONE 2013, 8, e63012. [CrossRef]

56. Markowitz, J.; Carson, W.E. Review of S100A9 biology and its role in cancer. Biochim. Biophys. Acta 2013, 1835, 100-109. [CrossRef]

57. Hage-Sleiman, R.; Herveau, S.; Matera, E.-L.; Laurier, J.-F.; Dumontet, C. Silencing of Tubulin Binding Cofactor $C$ modifies microtubule dynamics and cell cycle distribution and enhances sensitivity to gemcitabine in breast cancer cells. Mol. Cancer Ther. 2011, 10, 303-312. [CrossRef]

58. Maxwell, S.A.; Cherry, E.M.; Bayless, K.J. Akt, 14-3-3 $\zeta$, and vimentin mediate a drug-resistant invasive phenotype in diffuse large B-cell lymphoma. Leuk. Lymphoma 2011, 52, 849-864. [CrossRef]

59. Zhang, Q.; Zhao, Z.; Ma, Y.; Wang, H.; Ma, J.; He, X.; Zhang, D. Combined expression of S100A4 and annexin A2 predicts disease progression and overall survival in patients with urothelial carcinoma. Urol. Oncol. 2014, 32, 798-805. [CrossRef]

60. Peng, B.; Guo, C.; Guan, H.; Liu, S.; Sun, M.-Z. Annexin A5 as a potential marker in tumors. Clin. Chim. Acta 2014, 427, 42-48. [CrossRef]

61. Sun, C.-B.; Zhao, A.-Y.; Ji, S.; Han, X.-Q.; Sun, Z.-C.; Wang, M.-C.; Zheng, F.-C. Expression of annexin A5 in serum and tumor tissue of patients with colon cancer and its clinical significance. World J. Gastroenterol. 2017, 23, 7168-7173. [CrossRef]

62. Sun, X.; Liu, S.; Wang, J.; Wei, B.; Guo, C.; Chen, C.; Sun, M.-Z. Annexin A5 regulates hepatocarcinoma malignancy via CRKI/II-DOCK180-RAC1 integrin and MEK-ERK pathways. Cell Death Dis. 2018, 9, 637. [CrossRef]

63. Kim, J.-K.; Louhghalam, A.; Lee, G.; Schafer, B.W.; Wirtz, D.; Kim, D.-H. Nuclear lamin A/C harnesses the perinuclear apical actin cables to protect nuclear morphology. Nat. Commun. 2017, 8, 2123. [CrossRef]

64. Zuo, L.; Zhao, H.; Yang, R.; Wang, L.; Ma, H.; Xu, X.; Zhou, P.; Kong, L. Lamin A/C might be involved in the EMT signaling pathway. Gene 2018, 663, 51-64. [CrossRef] [PubMed]

65. Taheri, F.; Isbilir, B.; Müller, G.; Krieger, J.W.; Chirico, G.; Langowski, J.; Tóth, K. Random motion of chromatin is influenced by lamin A interconnections. Biophys. J. 2018, 114, 2465-2472. [CrossRef] [PubMed]

66. Contrepois, K.; Coudereau, C.; Benayoun, B.A.; Schuler, N.; Roux, P.-F.; Bischof, O.; Courbeyre, R.; Carvalho, C.; Thuret, J.-Y.; Ma, Z.; et al. Histone variant H2A.J accumulates in senescent cells and promotes inflammatory gene expression. Nat. Commun. 2017, 8, 14995. [CrossRef] [PubMed]

67. Workman, P.; Aboagye, E.O.; Balkwill, F.; Balmain, A.; Bruder, G.; Chaplin, D.J.; Double, J.A.; Everitt, J.; Farningham, D.A.H.; Glennie, M.J.; et al. Guidelines for the welfare and use of animals in cancer research. Br. J. Cancer 2010, 102, 1555-1577. [CrossRef] [PubMed]

68. Valo, I.; Raro, P.; Boissard, A.; Maarouf, A.; Jézéquel, P.; Verriele, V.; Campone, M.; Coqueret, O.; Guette, C. OLFM4 expression in ductal carcinoma in situ and in invasive breast cancer cohorts by a SWATH-based proteomic approach. Proteomics 2019, 1800446. [CrossRef] [PubMed]

(C) 2020 by the authors. Licensee MDPI, Basel, Switzerland. This article is an open access article distributed under the terms and conditions of the Creative Commons Attribution (CC BY) license (http://creativecommons.org/licenses/by/4.0/). 